\title{
Pengontrolan Kecepatan Rotor BLDC UAV Berdasarkan Hasil Identifikasi menggunakan Metode Regresi
}

\section{ERWANI MERRY SARTIKA, MULIADY, RUDI SARJONO, VINCENSIUS YUVENS}

Teknik Elektro Universitas Kristen Maranatha, Indonesia

Email: erwanimerry@gmail.com

Received 9 Juni 2020 | Revised 25 Juni 2020 | Accepted 8 Juli 2020

\begin{abstract}
ABSTRAK
Penggunaan dan aplikasi motor Brushless DC cukup banyak di industri, namun masih cukup sulit untuk mengendalikannya. Pada penelitian sebelumnya telah dipelajari karakteristik parameter motor BLDC UAV menggunakan Metode Regresi untuk mengetahui hubungan antar parameter yang ada dalam sistem motor BLDC. Sinyal PWM merupakan salah satu yang menentukan kecepatan rotor dari BLDC. Pada penelitian ini identifikasi model motor BLDC hasil eksperimen digunakan untuk mengendalikan kecepatan rotor secara open loop dan closed loop. Pengendalian secara open loop menggunakan invers model hasil Metode Regresi menghasilkan kesalahan maksimal 3,77\% untuk kecepatan rotor lebih dari 3500 rpm. Sedangkan pada pengendalian secara closed loop menggunakan model hasil Metode Regresi dan pengendali PI (Proportional Integral) dengan $\mathrm{Kp}=1$ dan $\mathrm{Ki}=$ 5, secara simulasi menghasilkan kecepatan rotor dengan settling time 1 detik.
\end{abstract}

Kata kunci: motor BLDC, kecepatan rotor, identifikasi model, pengendalian

\begin{abstract}
The use and application of Brushless DC motors is quite a lot in the industry, but it is still quite difficult to control. In previous research the characteristics of UAV $B L D C$ motor parameters using the regression method to determine the relation of the parameters in the BLDC motor system. The PWM signal is one that determines the rotor speed of the BLDC. In this study the identification of the BLDC motor model experimental results is used to control the rotor speed in open loop and closed loop. Control with open loop using the inverse model of the Regression Method produces a maximum error of $3.77 \%$ for rotor speeds of more than 3500 rpm. Whereas control with closed loop using the model of the Regression Method and PI (Proportional Integral) controller with $K p=1$ and $K i=5$, the simulation produces rotor speed with a settling time of 1 second.
\end{abstract}

Keywords: BLDC motor, rotor speed, model identification, control 
Pengontrolan Kecepatan Rotor BLDC UAV Berdasarkan Hasil Identifikasi menggunakan Metoda Regresi

\section{PENDAHULUAN}

Motor DC Brushless mempunyai tiga fase permanen magnet motor yang membutuhkan tegangan DC sebagai suplai (Jaya \& Fauziah, 2017). Motor DC tanpa sikat (BLDC) menggunakan bahan semikonduktor untuk mengubah arah putarannya dalam menggerakkan motor (Fathoni \& Utomo, 2019). Motor BLDC banyak digunakan dalam aplikasi termasuk peralatan, otomotif, aerospace, elektronik konsumen, medis, peralatan industri otomatis dan instrumentasi. Dibandingkan dengan motor DC dengan sikat atau motor induksi, motor BLDC memiliki banyak keuntungan seperti efisiensi dan keandalan yang lebih tinggi, kebisingan akustik yang lebih rendah, dan handal (Vijay \& Arun Kishore, 2017).

Namun untuk mengendalikan kecepatan motor Brushless DC cukup sulit terutama bila diterapkan pada kendaraan listrik yang bekerja pada sistem beban dinamis (Dwivedi \& Tiwari, 2013). Dalam usaha pengendalian dari motor BLDC, perlu diketahui karakteristik/hubungan antara pengontrolan duty cycle input PWM yang masuk ke ESC dengan tegangan dan frekuensinya yang akan mempengaruhi kecepatan rotor dan arus armature yang bekerja pada motor BLDC (Sartika, 2019). Secara hardware disain rangkaian pengendali juga dirancang untuk memperbaiki arah arus yang mengikuti ke stator (Hazari \& Jahan, 2014) (Seol, dkk, 2017). Memodelkan secara matematis motor Brushless DC secara fisik dan simulasinya dilakukan untuk mengendalikan kecepatan motor BLDC (Azzumar, 2012). Metode Regresi digunakan untuk mendapatkan persamaan karakteristik BLDC secara sistematis, dan model karakteristik tersebut diperoleh dan divalidasi melalui hasil eksperimen yang dilakukan pada motor BLDC UAV (Sartika, dkk, 2019). Metode Regresi juga digunakan untuk memprediksi posisi motor untuk mencapai posisi yang diinginkan sebagai pengendalian secara open loop (Sartika, dkk, 2019).

Pada penelitian ini pengendalian kecepatan rotor Brushless DC dilakukan menggunakan persamaan model hasil identifikasi (kecepatan rotor terhadap sinyal PWM) dan invers persamaan model (sinyal PWM terhadap kecepatan rotor) menggunakan Metode Regresi (Chapra \& Canale, 2015). Pengendalian kecepatan rotor Brushless DC dilakukan secara open loop dan closed loop. Untuk pengendalian secara open loop pengendalian menggunakan Metode Regresi untuk mendapatkan persamaan invers model hasil identifikasi plant motor BLDC. Sedangkan untuk pengendalian secara closed loop, identifikasi menggunakan Metode Regresi digunakan untuk mendapatkan persamaan model plant motor BLDC agar dapat dilakukan simulasi untuk mendapatkan parameter PID kontrol yang digunakan untuk mengendalikan kecepatan rotor.

\section{METODOLOGI PENELITIAN}

Pada bagian perancangan ini diawali dengan tinjauan pustaka untuk mengetahui parameter yang mempengaruhi karakteristik plant BLDC, dilanjutkan dengan mendapatkan model dari plant BLDC menggunakan Metode Regresi. Selain itu model invers plant BLDC juga dicari menggunakan Metode Regresi. Hasil kedua model tersebut selanjutnya digunakan untuk mengendalikan kecepatan rotor BLDC. Untuk sistem pengendalian secara open loop, kedua model yang diperoleh digunakan untuk mengendalikan kecepatan rotor BLDC, sedangkan untuk pengendalian sistem secara closed loop hanya menggunakan model plant BLDC dan pengendalian dilakukan secara simulasi. Seluruh data dan pengendalian yang diperoleh kemudian dianalisis dan disimpulkan sebagai hasil dari penelitian ini.

Perancangan pada penelitian ini mengacu pada hasil penelitian sebelumnya yaitu simulasi dari pemodelan motor BLDC UAV (Sartika, 2019). Dari simulasi tersebut, diperoleh pengaruh 
masukan/keluaran dari setiap bagian yang terpasang pada motor BLDC. Penelitian ini mengacu pada rangkaian seperti ditunjukkan pada Gambar 1 . Sumber tegangan dan sinyal input berupa PWM (\% duty cycle) diberikan pada Electronic Speed Contro/(ESC) agar menggerakkan motor BLDC. Untuk mengendalikan kecepatan rotor yang diinginkan diperlukan pengendali agar bergerak sesuai kecepatan yang diinginkan.

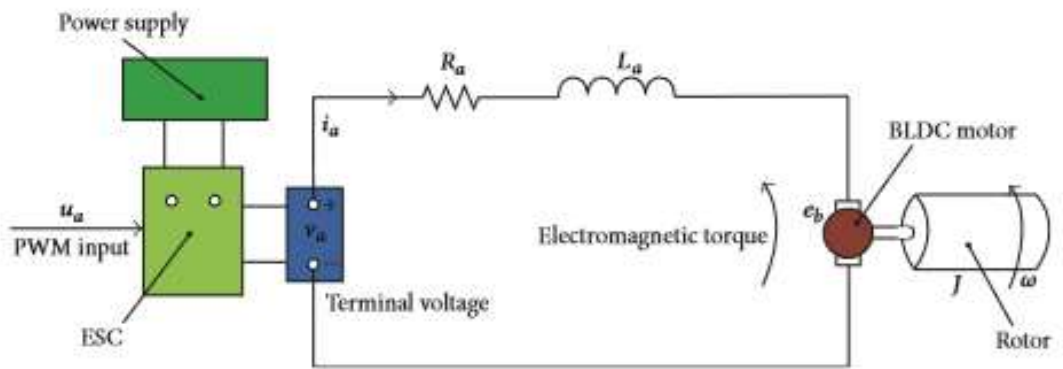

Gambar 1. Rangkaian Konfigurasi Sistem Motor BLDC (Xiang, dkk, 2015)

Sebelum pengendalian dilakukan, perlu diketahui model hasil identifikasi karakteristik dari motor BLDC UAV melalui data eksperimen. Hasil identifikasi karakteristik yang telah dilakukan menunjukkan bahwa pengendalian kecepatan rotor BLDC UAV lebih presisi berdasarkan sinyal PWM (\% duty cycle) dan frekuensi sinyal keluaran ESC (E. Sartika, dkk, 2019). Pada penelitian ini kecepatan rotor BLDC akan dikendalikan berdasarkan sinyal PWM (\% duty cycle).

Tabel 1. Pengambilan Data Sinyal PWM (\% duty cycle) terhadap Kecepatan Rotor (rpm)

\begin{tabular}{|c|c|c|}
\hline No & PWM (\% duty cycle) & W Kecepatan rotor (rpm) \\
\hline 1 & 6 & 1265 \\
\hline 2 & 6,2 & 1786 \\
\hline 3 & 6,4 & 2212 \\
\hline 4 & 6,6 & 2555 \\
\hline 5 & 6,8 & 2844 \\
\hline 6 & 7 & 3082 \\
\hline 7 & 7,2 & 3301 \\
\hline 8 & 7,4 & 3502 \\
\hline 9 & 7,6 & 3638 \\
\hline 10 & 7,8 & 3757 \\
\hline 11 & 8 & 3858 \\
\hline 12 & 8,3 & 3993 \\
\hline 13 & 8,5 & 4066 \\
\hline 14 & 8,7 & 4126 \\
\hline 15 & 9 & 4199 \\
\hline 16 & 9,2 & 4252 \\
\hline 17 & 9,5 & 4309 \\
\hline 18 & 9,7 & 4345 \\
\hline 19 & 9,9 & 4383 \\
\hline 20 & 10 & 4404 \\
\hline
\end{tabular}

Pada pengendalian kecepatan rotor BLDC akan menggunakan 2 hasil identifikasi model yaitu identifikasi model motor BLDC (sinyal PWM terhadap kecepatan rotor) dan invers identifikasi 
Pengontrolan Kecepatan Rotor BLDC UAV Berdasarkan Hasil Identifikasi menggunakan Metoda Regresi

model motor BLDC (kecepatan rotor terhadap sinyal PWM). Data pengambilan kecepatan rotor ditunjukkan pada Tabel 1, dengan sumber tegangan sebesar 10 Volt untuk berbagai sinyal input PWM $u_{a}$ (\% duty cycle).

Berdasarkan data pada Tabel 1 dibuat grafik hubungan antara kecepatan rotor (rpm) terhadap sinyal PWM (10000 x \% duty cycle) menggunakan Metode Regresi Polinomial seperti ditunjukkan pada Gambar 2. Pengali dalam sinyal PWM dilakukan agar hasil identifikasi model menjadi lebih presisi, sedangkan pada perhitungan akhir tetap dikembalikan ke nilai aslinya (dibagi 10000) seperti yang ditunjukkan pada Persamaan (1). Model yang dihasilkan berupa sistem orde 3 yang diperoleh menggunakan Metode Regresi Polinomial dengan koefisien korelasi kuadrat $\left(R^{2}\right)$ sebesar 0,9943 . Gambar 2 adalah grafik kecepatan rotor terhadap sinyal PWM (invers identifikasi model motor BLDC).

$$
\begin{gathered}
\text { Sinyal PWM }(\% \text { duty cycle })=\left(3.10^{3} \omega^{3}-0,021 \omega^{2}+51,171 \omega+21876\right) / 10000 \\
\mathrm{R}^{2}=0,9943
\end{gathered}
$$

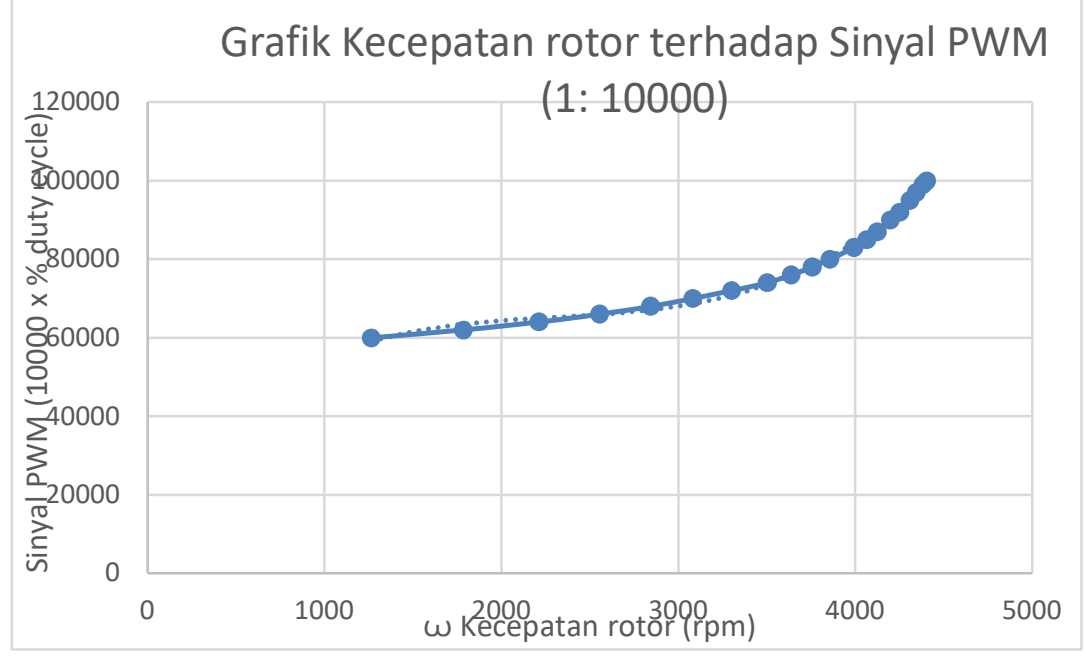

Gambar 2. Hubungan antar Kecepatan Rotor terhadap Sinyal PWM rotor BLDC

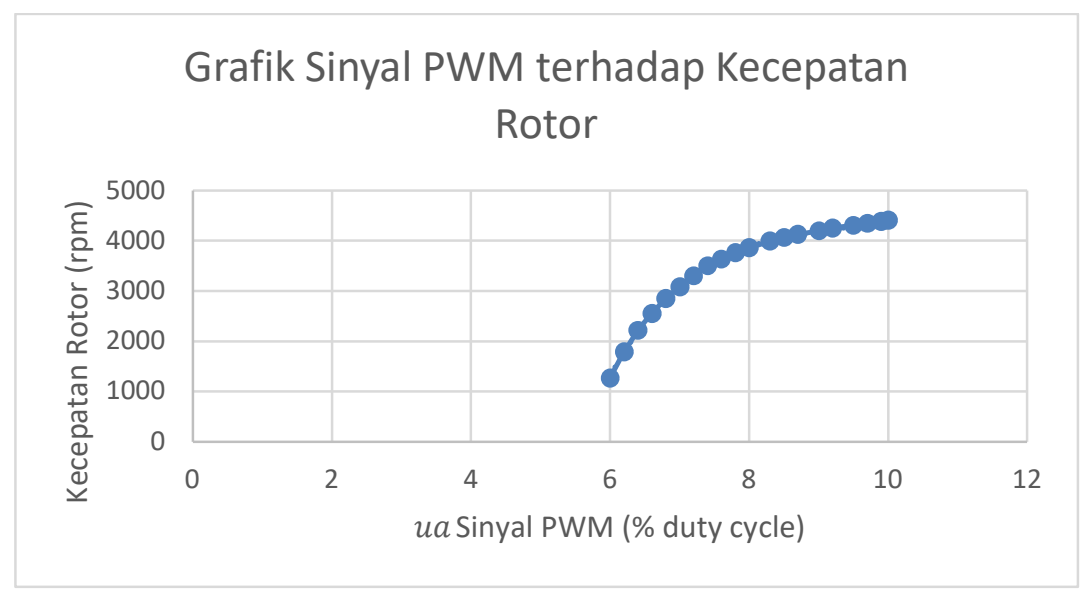

Gambar 3. Hubungan antar Sinyal PWM terhadap Kecepatan Rotor BLDC 
Selain itu berdasarkan data pada Tabel 1 grafik hubungan antara sinyal PWM (\% duty cycle) terhadap kecepatan rotor (rpm) ditunjukkan pada Gambar 3. Model yang diperoleh adalah seperti yang ditunjukkan pada Persamaan (2). Model berupa sistem orde 3 yang diperoleh menggunakan Metode Regresi Polinomial dengan koefisien korelasi kuadrat $\left(R^{2}\right)$ sebesar 0,9993 .

$$
\begin{gathered}
\text { Kecepatan rotor }(\mathrm{rpm})=76,212 u_{a}{ }^{3}-2082,1 u_{a}{ }^{2}+19154 u_{a}-55106 \\
\mathrm{R}^{2}=0,9993
\end{gathered}
$$

Pada perancangan ini, pengendali yang dibuat ada 2 jenis yaitu pengendali kecepatan rotor BLDC UAV secara open loop dan closed loop. Invers model hasil identifikasi digunakan sebagai algoritma pengendalian kecepatan rotor BLDC UAV secara open loop. Proses pengendalian kecepatan rotor BLDC secara maksimum dilakukan menggunakan invers dari model plant motor BLDC UAV. Masukan berupa set point rpm oleh pengendali yang diperoleh dari invers model dari plant motor BLDC UAV digunakan untuk mengendalikan plant motor BLDC UAV untuk menghasilkan kecepatan rotor BLDC yang diinginkan seperti ditunjukkan pada diagram blok Gambar 3.

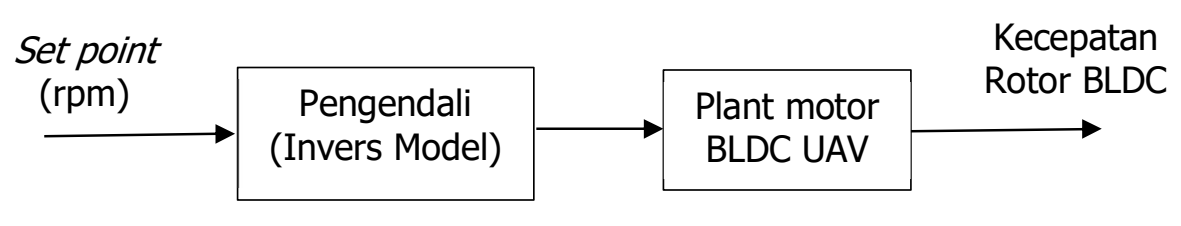

\section{Gambar 3. Diagram Blok Sistem Pengendalian Kecepatan Rotor BLDC secara Open Loop}

Sedangkan proses pengendalian kecepatan rotor Brushless DC UAV secara closed loop, model hasil identifikasi digunakan sebagai plant rotor BLDC UAV sehingga dapat digunakan untuk merancang parameter pengendali PID secara simulasi untuk mengendalikan kecepatan rotor yang terbaik. Parameter PID yang dicari terlebih dahulu dari simulasi sehingga dapat digunakan untuk mengendalikan plant motor BLDC secara real dengan cara menambah sensor kecepatan rotor pada BLDC. Gambar 4 adalah diagram blok sistem pengendalian kecepatan rotor BLDC secara closed loop yaitu set point berupa kecepatan motor BLDC yang diinginkan diselisihkan dengan pembacaan sensor kecepatan rotor BLDC. Hasil selisih kecepatan rotor (error kecepatan rotor) diolah oleh pengontrol PID agar dapat mengendalikan kecepatan rotor plant motor BLDC UAV sampai set point tercapai sesuai keinginan.

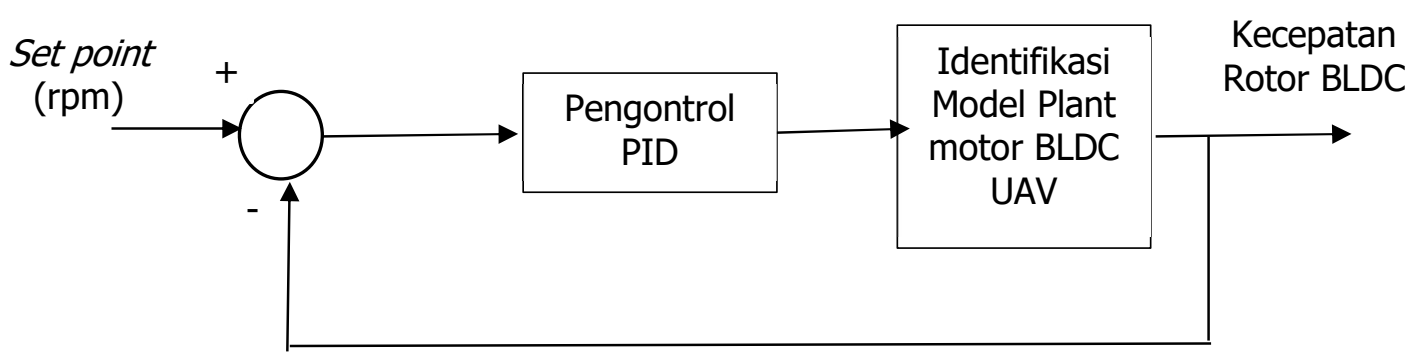

Gambar 4. Diagram Blok Sistem Pengendalian Kecepatan Rotor BLDC secara Closed Loop 
Pengontrolan Kecepatan Rotor BLDC UAV Berdasarkan Hasil Identifikasi menggunakan Metoda Regresi

\section{HASIL DAN PEMBAHASAN}

Dalam data pengamatan ini akan ditunjukkan hasil pengendalian kecepatan rotor BLDC berdasarkan persamaan model hasil eksperimen secara open loop, dan hasil pengendalian kecepatan rotor BLDC yang disimulasikan secara closed loop.

Untuk hasil pemodelan pada bagian perancangan berupa Persamaan (1) yaitu hubungan antara kecepatan rotor $(\mathrm{rpm})$ terhadap sinyal PWM, maka pengendalian yang digunakan adalah pengendalian kecepatan rotor BLDC secara open loop. Pada pengendalian ini menggunakan diagram blok sistem pengendalian seperti yang ditunjukkan pada Gambar 3. Persamaan (1) digunakan sebagai pengendali yang akan menghasilkan sinyal kontrol berupa sinyal PWM (\% duty cycle) yang diperlukan agar BLDC dapat menghasilkan kecepatan rotor yang diinginkan. Keberhasilan pengendali open loop diukur dari seberapa besar kesalahan pengendalian untuk mengetahui spesifikasi dari pengendalian yang diperoleh.

Tabel 2. Validasi Pengendalian Kecepatan Rotor BLDC Berdasarkan Model Invers (Kecepatan Rotor terhadap Sinyal PWM)

\begin{tabular}{|c|c|c|c|c|c|}
\hline $\begin{array}{c}\text { Duty cycle } \\
\text { set point }\end{array}$ & $\begin{array}{c}\text { RPM set } \\
\text { point }\end{array}$ & $\begin{array}{c}\text { Duty cycle hasil } \\
\text { Model }\end{array}$ & $\begin{array}{c}\text { RPM hasil } \\
\text { pengendalian } \\
\text { berdasar Model } \\
\text { (pengukuran) }\end{array}$ & $\begin{array}{c}\text { Kesalahan } \\
\text { pengendalian } \\
\text { berdasarkan } \\
\text { Model }\end{array}$ & $\begin{array}{c}\text { \% Kesalahan } \\
\text { pengendalian } \\
\text { berdasarkan } \\
\text { Model }\end{array}$ \\
\hline 6 & 1265 & 5,9 & 1023 & 242 & 19,13 \\
\hline 6,2 & 1786 & 6,3 & 1993 & 207 & 11,59 \\
\hline 6,4 & 2212 & 6,5 & 2371 & 159 & 7,19 \\
\hline 6,6 & 2555 & 6,6 & 2515 & 40 & 1,57 \\
\hline 6,8 & 2844 & 6,7 & 2702 & 142 & 4,99 \\
\hline 7 & 3082 & 6,8 & 2815 & 267 & 8,66 \\
\hline 7,2 & 3301 & 7 & 3062 & 239 & 7,24 \\
\hline 7,4 & 3502 & 7,2 & 3283 & 219 & 6,25 \\
\hline 7,6 & 3638 & 7,5 & 3555 & 83 & 2,28 \\
\hline 7,8 & 3757 & 7,7 & 3688 & 69 & 1,84 \\
\hline 8 & 3858 & 7,9 & 3805 & 53 & 1,37 \\
\hline 8,3 & 3993 & 8,2 & 3987 & 6 & 0,15 \\
\hline 8,5 & 4066 & 8,4 & 4065 & 1 & 0,02 \\
\hline 8,7 & 4126 & 8,6 & 4133 & 7 & 0,17 \\
\hline 9 & 4199 & 8,9 & 4221 & 22 & 0,52 \\
\hline 9,2 & 4252 & 9 & 4243 & 9 & 0,21 \\
\hline 9,5 & 4309 & 9,2 & 4288 & 21 & 0,49 \\
\hline 9,7 & 4345 & 9,4 & 4329 & 16 & 0,37 \\
\hline 9,9 & 4383 & 9,5 & 4354 & 29 & 0,66 \\
\hline 10 & 4404 & 9,6 & 4370 & 34 & 0,77 \\
\hline & & & & Rata-rata & 3,77 \\
\hline
\end{tabular}

Tabel 2 merupakan hasil pengujian pengendalian secara open loop dengan menguji seluruh data kecepatan rotor BLDC sebagai set-point (yang diinginkan), dan dihasilkan rata-rata kesalahan pengendalian sebesar 3,77 \%. Hasil pengendalian open loop yang dihasilkan menunjukkan bahwa \% kesalahan pengendalian cukup kecil sehingga pengendalian open loop ini layak digunakan untuk mengendalikan kecepatan rotor BLDC. 
Tabel 3 adalah pengujian pengendalian kecepatan rotor BLDC dengan menggunakan data yang berbeda dengan data yang digunakan untuk menentukan model rotor BLDC (Tabel 2). Hasilnya menunjukkan bahwa kecepatan rotor BLDC yang kesalahannya di bawah rata-rata \% kesalahan pengendalian adalah pada kecepatan di atas $3500 \mathrm{rpm}$ (warna merah muda).

Maka berdasarkan Tabel 2 dan Tabel 3 dapat disimpulkan bahwa model yang diperoleh akan mempunyai kesalahan lebih kecil dari 3,77\% jika diterapkan untuk mengendalikan kecepatan rotor BLDC secara open loop untuk kecepatan yang lebih besar dari 3500 rpm.

Tabel 3. Validasi Pengendalian Kecepatan Rotor BLDC Berdasarkan Model Invers (Kecepatan Rotor terhadap Sinyal PWM) menggunakan Data yang Berbeda dengan Data Model.

\begin{tabular}{|c|c|c|c|c|}
\hline $\begin{array}{c}\text { RPM set } \\
\text { point }\end{array}$ & duty cycle & $\begin{array}{c}\text { RPM hasil } \\
\text { pengukuran }\end{array}$ & $\begin{array}{c}\text { Kesalahan } \\
\text { Model }\end{array}$ & $\begin{array}{c}\text { \% Kesalahan } \\
\text { Model }\end{array}$ \\
\hline 1300 & 5,9 & 979,7 & 320,3 & 24,64 \\
\hline 1500 & 6,2 & 1811 & 311 & 20,73 \\
\hline 2000 & 6,4 & 2239 & 239 & 11,95 \\
\hline 2100 & 6,5 & 2385 & 285 & 13,57 \\
\hline 2200 & 6,5 & 2385 & 185 & 8,41 \\
\hline 2400 & 6,5 & 2385 & 15 & 0,63 \\
\hline 2600 & 6,6 & 2593 & 7 & 0,27 \\
\hline 3000 & 6,7 & 2744 & 256 & 8,53 \\
\hline 3200 & 6,9 & 3037 & 163 & 5,09 \\
\hline 3600 & 7,4 & 3518 & 82 & 2,28 \\
\hline 3700 & 7,6 & 3663 & 37 & 1,00 \\
\hline 3800 & 7,8 & 3805 & 5 & 0,13 \\
\hline 3900 & 8 & 3909 & 9 & 0,23 \\
\hline 4100 & 8,5 & 4104 & 4 & 0,10 \\
\hline 4200 & 8,9 & 4229 & 29 & 0,69 \\
\hline
\end{tabular}

Untuk hasil pemodelan pada bagian perancangan berupa Persamaan (2) yaitu hubungan antara sinyal PWM terhadap kecepatan rotor (rpm), maka pengendalian yang digunakan adalah pengendalian kecepatan rotor BLDC secara closed loop. Pada pengendalian ini menggunakan diagram blok sistem pengendalian seperti yang ditunjukkan pada Gambar 4. Persamaan (2) digunakan sebagai plant motor BLDC yang akan dikendalikan menggunakan pengendali PID yang akan menghasilkan sinyal kontrol berupa sinyal PWM (\% duty cycle) agar BLDC dapat menghasilkan kecepatan rotor yang diinginkan. Keberhasilan pengendali closed loop diukur dari seberapa cepat kecepatan rotor yang diinginkan dapat tercapai.

Simulink pengendalian kecepatan rotor BLDC secara closed loop ditunjukkan pada Gambar 4. Blok kontrol PID digunakan untuk mengendalikan plant motor BLDC secara simulasi menggunakan Simulink. Tuning parameter PID dilakukan secara trial and error sehingga diperoleh nilai parameter PID yang terbaik dengan mengukur kinerja dari respon kecepatan rotor BLDC setelah dikendalikan. Untuk sistem pengendalian secara closed loop ditunjukkan secara simulasi agar parameter PID yang diperoleh dapat digunakan secara real dengan menambah sensor kecepatan rotor pada motor BLDC. 


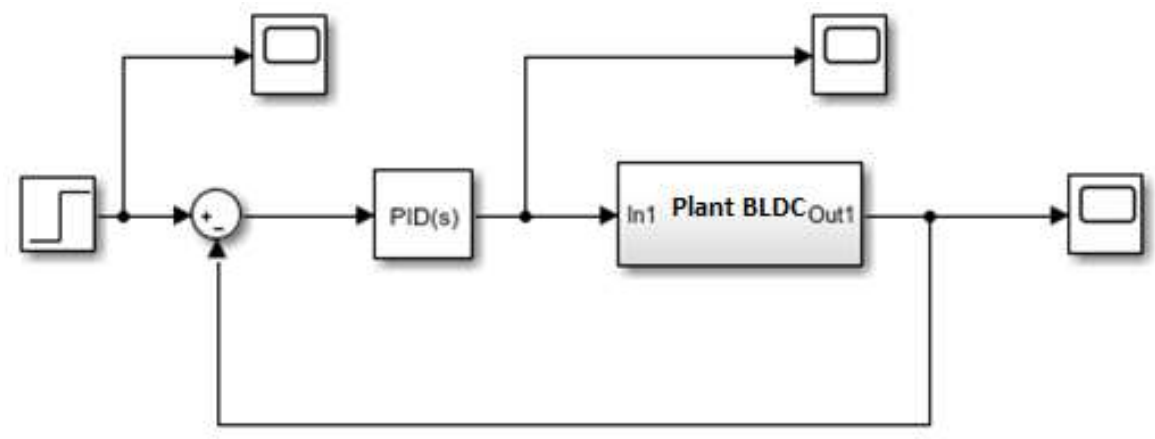

(a)

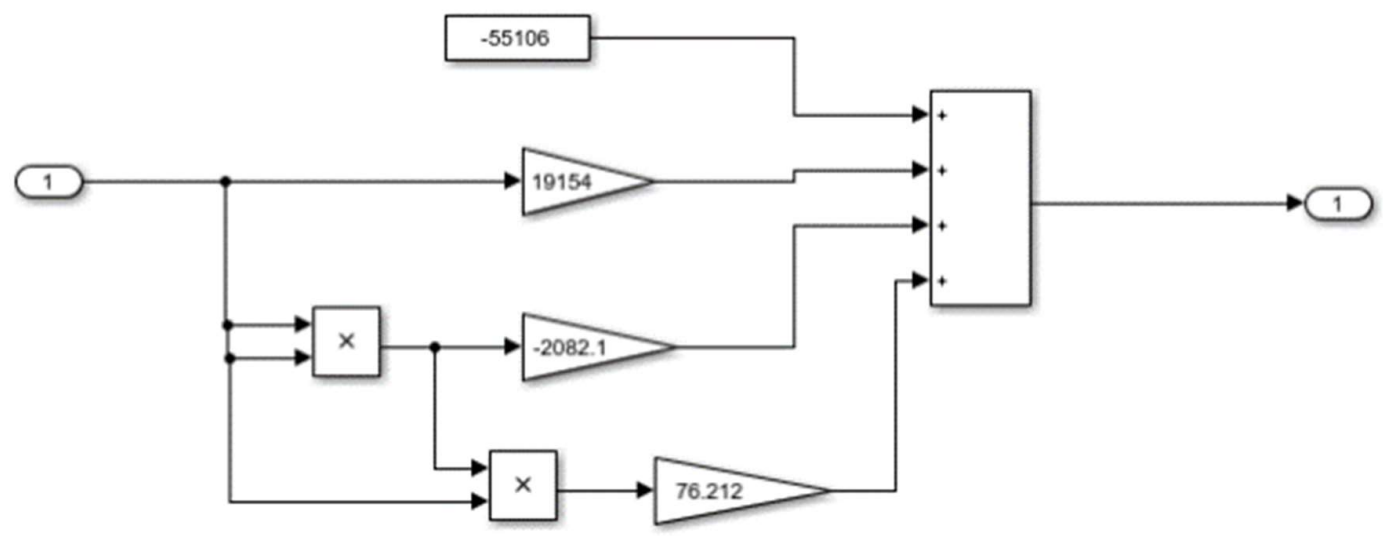

(b)

Gambar 4. (a) Simulink Pengendalian Kecepatan Rotor BLDC yang dikendalikan oleh Pengendali PI (b) Persamaan Model Kecepatan Rotor yang ada dalam Plant BLDC

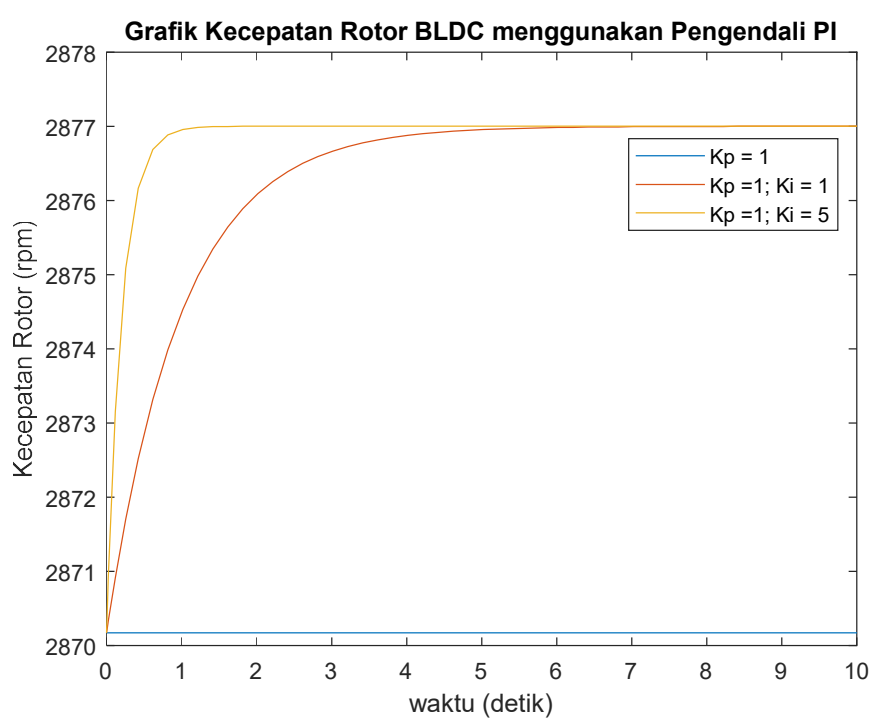

Gambar 5. Grafik Kecepatan Rotor BLDC (contoh: 2877 rpm) yang dikendalikan oleh Pengendali PI 
Simulasi hasil Pengendali PI (Proportional Integral) berhasil digunakan untuk mengendalikan plant motor BLDC (grafik warna kuning dan merah) karena grafik keluaran kecepatan pada plant BLDC menuju ke kecepatan yang diinginkan yaitu 2877 rpm seperti ditunjukkan pada Gambar 5. Untuk nilai $\mathrm{Kp}=1$ dan $\mathrm{Ki}=5$ (warna kuning) memberikan respon terbaik dengan settling time sebesar 1 detik. Untuk nilai $\mathrm{Kp}=1$ (warna biru) tidak dapat mencapai nilai kecepatan rotor yang diinginkan (ada offset) sehingga diperlukan nilai Ki. Untuk nilai $\mathrm{Kp}=1$ dan $\mathrm{Ki}=1$ (warna merah) kecepatan rotor sudah langsung dapat mencapai kecepatan rotor yang diinginkan, namun settling time dicapai dalam waktu 6 detik.

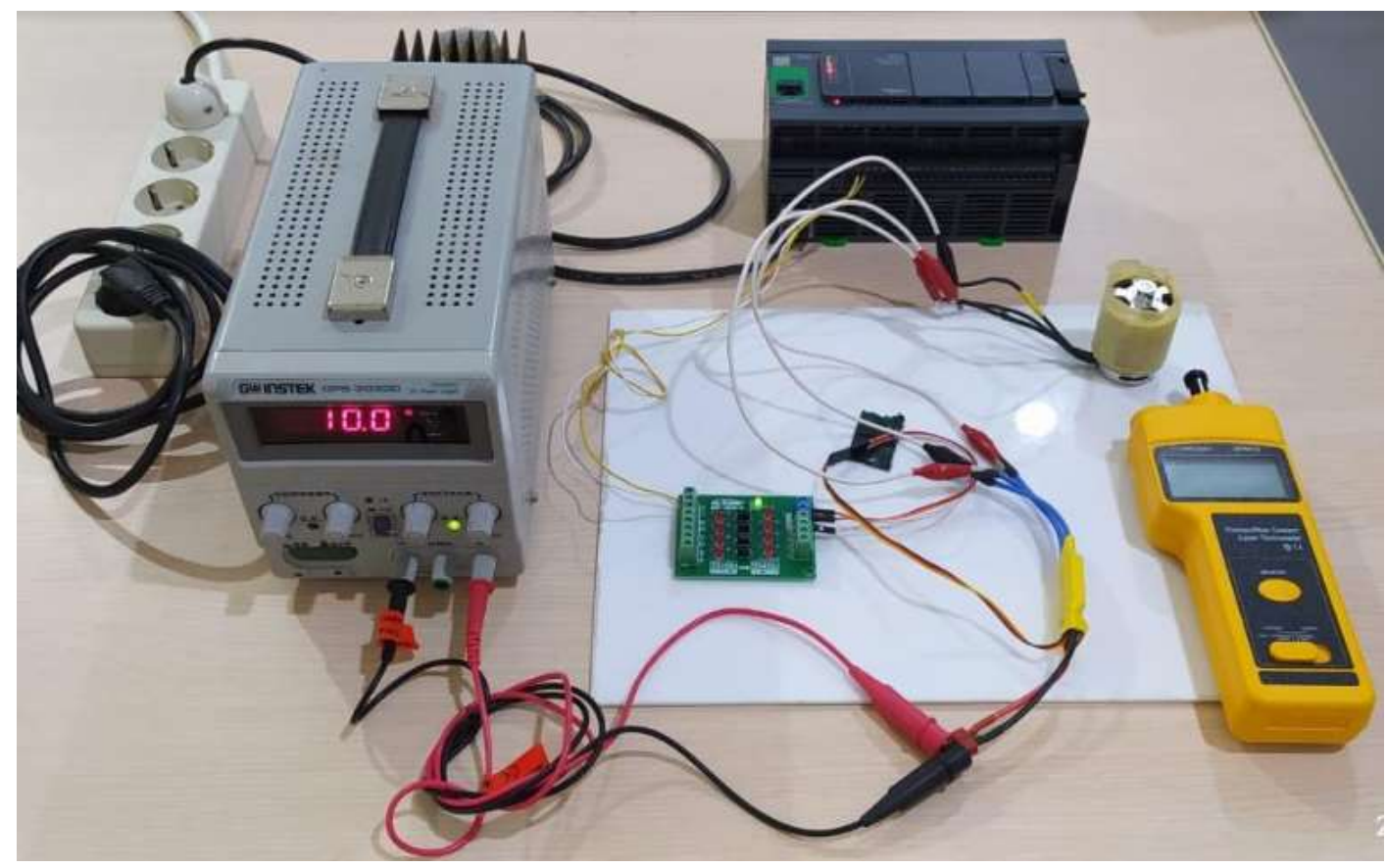

Gambar 6. Realisasi Pengambilan Data Karakteristik Motor BLDC

Gambar 6 adalah pemasangan rangkaian pada saat pengambilan data pada motor BLDC. Power supply digunakan sebagai input pada ESC, PLC diprogram sesuai persamaan yang diperoleh sehingga menghasilkan nilai duty cycle PWM yang diuji, optocoupler yang digunakan untuk mengonversi 24 Volt ke 5 Volt, dan kecepatan rotor diukur menggunakan Laser Tachometer.

\section{KESIMPULAN}

Pada penelitian ini telah berhasil dilakukan pengendalian kecepatan rotor pada motor BLDC UAV secara open loop (real) dan closed loop (simulasi). Pengendalian open loop menggunakan invers model yang diperoleh menggunakan Metode Regresi dengan maksimal kesalahan sebesar 3,77\% dan pengendalian akan baik bila diterapkan untuk mengendalikan kecepatan rotor lebih dari $3500 \mathrm{rpm}$. Untuk pengembangan selanjutnya pada sistem open loop dapat dilakukan prediksi kesalahan sehingga dapat mengurangi kesalahan dan dapat digunakan juga untuk pengendalian pada kecepatan yang cukup rendah. Sedangkan untuk pengendalian closed loop pada kecepatan rotor berhasil dilakukan secara simulasi menggunakan persamaan model plant motor BLDC UAV dengan menggunakan pengendali PI (Proportional Integral) yaitu nilai $\mathrm{Kp}=1$ dan $\mathrm{Ki}=5$ sehingga menghasilkan performansi settling time sebesar 1 detik. 
Pengontrolan Kecepatan Rotor BLDC UAV Berdasarkan Hasil Identifikasi menggunakan Metoda Regresi

Untuk pengembangan selanjutnya pengendalian closed loop dapat diterapkan pada plant motor BLDC UAV dengan menambahkan sensor kecepatan rotor secara permanen.

\section{DAFTAR RUJUKAN}

Azzumar, M. (2012). Pemodelan dan Simulasi Brushless DC Motor Kecil untuk Aplikasi Aktuator Sirip Roket.

Chapra, S. C., \& Canale, R. P. (2015). Numerical Methods for Engineers (seventh Ed). McGrawHill Science/Engineering/Math.

Dwivedi, A., \& Tiwari, A. N. (2013). A Review : Speed Control of Brushless DC Motor A Review: Speed Control of Brushless DC Motor. IJBSTR, December, (pp. 14-19). https://doi.org/10.13140/RG.2.2.10646.86087

E. Sartika; Muliady; S. Rudi. (2019). Identifikasi Karakteristik Arus Armature dan Kecepatan Rotor BLDC UAV menggunakan Metode Regresi. Seminar Nasional Energi Telekomunikasi Dan Otomasi, (pp. 74-82).

Fathoni, K., \& Utomo, A. B. (2019). Perancangan Kendali Optimal pada Motor Arus Searah Tanpa Sikat melalui Metode LQRI. ELKOMIKA: Jurnal Teknik Energi Elektrik, Teknik

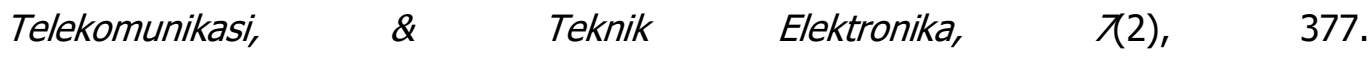
doi:https://doi.org/10.26760/elkomika.v7i2.377

https://doi.org/http://dx.doi.org/10.26760/elkomika.v7i2.377 Mei 2019

Hazari, R., \& Jahan, E. (2014). Design of a Brushless DC ( BLDC ) Motor Controller. International Conference on Electrical Engineering and Information \& Communication Technology (ICEEICT) 2014, December.

Jaya, A., \& Fauziah, M. B. (2017). Design of PID-Fuzzy for Speed Control of Brushless DC Motor in Dynamic Electric Vehicle to Improve Steady-State Performance. 2017 International Electronics Symposium on Engineering Technology and Applications (IESETA), (pp. 179-184).

Sartika, E. M. (2019). Simulasi Karakteristik Motor BLDC UAV. Seminar FORTEI 2019 Edisi Khusus Prosiding FORTEI 2019 Vol 5, No 1.1 , 1-4. http://ejournal.unp.ac.id/index.php/jtev/article/view/106120

Sartika, E. M., Sarjono, R., \& Chrisophras, H. X. (2019). Sistem Pick and Place Dua Derajat Kebebasan menggunakan Metode Regresi. ELKOMIKA: Jurnal Teknik Energi Elektrik, Teknik Telekomunikasi, \& Teknik Elektronika, オ(3), 521. doi:https://doi.org/10.26760/elkomika.v7i3.521

Seol, H. S., Lim, J., Kang, D. W., Park, J. S., \& Lee, J. (2017). Optimal Design Strategy for 
Improved Operation of IPM BLDC Motors with Low-Resolution Hall Sensors. IEEE Transactions on Industrial Electronics, 64(12), 9758-9766. https://doi.org/10.1109/TIE.2017.2716908

Vijay, S., \& Arun Kishore, W. C. (2017). One-cycle control of brushless DC motor. Proceedings of 2017 11th International Conference on Intelligent Systems and Control, ISCO 2017, (pp. 150-154). https://doi.org/10.1109/ISCO.2017.7855971

Xiang, C., Wang, X., Ma, Y., \& Xu, B. (2015). Practical Modeling and Comprehensive System Identification of a BLDC Motor. Hindawi Publishing Corporation Mathematical Problems in Engineering Volume 2015, Article ID 879581, 11 Pages Http://Dx.Doi.Org/10.1155/2015/879581 Research, 2015. 